\title{
PESQUISAS, RELATOS E NARRATIVAS SOBRE ARTE CIRCENSE: 13 PONTOS DE VISTA
}

\author{
José Rafael Madureira \\ Universidade Federal de Alagoas, Maceió, Alagoas, Brasil.
}

Circo: horizontes educativos é uma coletânea organizada em 13 capítulos que reúne 17 autores, entre artistas, educadores e acadêmicos brasileiros, argentinos, peruanos e espanhóis, dispostos a contribuir com o debate sobre as artes circenses na sociedade contemporânea. As abordagens ultrapassam os "horizontes educativos" previstos, circunscrevendo temas como história, formação profissional, desenvolvimento infantil, antropologia social, políticas públicas, produção cultural e memória. Os textos dos autores estrangeiros são apresentados em seu idioma original (espanhol), o que garante à obra um status de internacionalidade.

Após breve apresentação feita pelos organizadores, a obra inicia-se com o texto "Aprendizes permanentes: circenses e a construção da produção do conhecimento no processo histórico", de Erminia Silva. A autora, cuja produção acadêmica serve de guia e referência para vários autores da coletânea, apresenta uma narrativa histórica do "circo-família", uma forma coletiva e familiar de transmissão de saberes e práticas que entrou em declínio em meados de 1950. O processo foi complexo e multifacetado, o que obrigou as famílias de artistas a revelar os "segredos" do circo para leigos. Essa abertura, embora tenha enfraquecido significativamente a tradição do circo-família, possibilitou que a arte circense permanecesse viva, fora das lonas, integrando-se aos processos de formação de artistas da cena, performers e educadores.

No capítulo 2, "O circo e a formação em artes cênicas", Mario Fernando Bolognesi descreve a busca de coletivos artísticos brasileiros pelas artes circenses, um processo iniciado em meados de 1970 e que se efetivou a partir de 1978 com a abertura da primeira escola brasileira de circo: a Academia Piolin de Artes Circenses (SP). Em seguida, o autor apresenta um relato sobre o Laboratório de Artes Circenses, um espaço de pesquisa prático-teórica sobre o ofício cômico criado em 2007 no Instituto de Artes da UNESP e integrado à graduação em Artes Cênicas. Bolognesi apresenta também alguns dados sobre um experimento realizado nesse laboratório com o propósito de verificar de que modo o ensino das atividades circenses contribui para a formação de aprendizes e praticantes de artes cênicas.

No capítulo 3, "Escola Nacional de Circo: desafios na gestão de um espaço cultural público de formação profissional", Zezo Oliveira faz um relato de sua experiência como diretor da Escola Nacional de Circo (2005-2013), instituição de referência na formação profissional em artes circenses fundada em 1982. Oliveira apresenta extratos do projeto pedagógico da escola, entre outros documentos oficiais (leis, portarias, resoluções), e discute os processos político-culturais, financeiros e administrativos que envolvem a gestão pública de um curso público de formação profissional, o que possibilita ao leitor um entendimento razoável dos problemas enfrentados por uma instituição de grande porte.

O capítulo 4, "Notas sobre a formação circense no Brasil: do circo de lona às escolas especializadas", de Rodrigo Duprat, inicia-se com a descrição do panorama histórico das 
escolas de circo no Brasil e, em seguida, apresenta a temática proposta a partir de duas categorias: o circo como recurso educativo ou espaço de lazer e o circo como profissão. Diante de substanciais dados e reflexões, Duprat aponta para a urgência em pensarmos com seriedade sobre a criação de graduações em artes circenses, o que iria contribuir de um modo efetivo para a conquista de maior legitimidade na área.

No capítulo 5, "La formación del artista circense en Argentina: una historia de revalorización, innovación y desafío", Julieta Infantino traz alguns dados oriundos de suas investigações antropológicas sobre o circo na Argentina. Para a autora, o circo foi sistematicamente desvalorizado durante um longo período de ditadura militar. A pesquisa abarcou desde os anos de 1980, quando, pela primeira vez, os "segredos" da tradição circense foram transmitidos a leigos, até o início do século XXI, registrado como o boom dos espaços de ensino de artes circenses. Para Infantino, o início do século XXI foi seriamente impactado pelo neoliberalismo econômico de Menem, o que levou os circenses a ampliar o mercado, agora destinado às crianças, aos jovens e adultos como espaço de prática corporal ou lazer. A nova tendência trouxe novas concepções pedagógicas que se contrapunham às abordagens mecanicistas de corpo, uma perspectiva que impulsionou a oferta de projetos vinculados à área do circo social.

O capítulo 6, "La formación artística en circo: estrategias de la Federación Europea de Escuelas de Circo Profesionales (FEDEC)", de Donald B. Lehn, traz instigantes apontamentos sobre a formação dos artistas circenses europeus diante de um mercado cultural altamente competitivo e ávido por novidades, o que tem levado os profissionais a buscar novas estratégias de criação e performance capazes de lidar com todas as variáveis presentes na produção de um espetáculo circense, desde aspectos técnico-criativos até aspectos de gestão da carreira profissional. $\mathrm{O}$ autor apresenta ainda algumas ações que foram organizadas pela FEDEC com o intuito de apoiar a formação e a atualização dos artistas.

O capítulo 7, "La Tarumba - circo peruano", de Fernando Zevallos Villalobos e Geraldine Sakuda Oshiro, é um comovente relato sobre a história do circo no Peru. Para os autores, o golpe militar de 1968 instaurou um clima de autoritarismo e negação das expressões culturais e artísticas nacionais que quase dizimou a forte tradição circense do país. Em 1983, na contramão dessas ondas de terror e desesperança, nasceu La Tarumba, uma trupe de rua fortemente engajada com as questões sociais, culturais e políticas do país. Esse grupo, que se apresenta hoje como expoente do mercado cultural peruano e internacional, definiu uma perspectiva inédita para a tradição circense peruana: o aspecto pedagógico da formação humana. Essa proposta, em linhas gerais, organiza-se a partir de três eixos: o jogo, o afeto e a criatividade, desenvolvidos num ambiente de muita experimentação, troca e acolhimento.

No capítulo 8, “O circo e sua contribuição para a educação escolar”, Teresa Ontañón Barragán infere que os problemas recorrentes do sistema educacional brasileiro dificultam sensivelmente a implementação de novas perspectivas educacionais. Para a autora, antes de se pensar em levar o circo à escola, é preciso repensar o formato da escola convencional, extremamente obtuso. Ao longo do texto, Barragán apresenta possibilidades de aproximação entre a escola e as artes do circo na tentativa de conceber uma educação corporal e estética que valorize o potencial criativo de cada um, minimizando a competitividade entre os indivíduos e valorizando a autonomia em todas as etapas do processo pedagógico.

O capítulo 9, "Novo status para o circo no Centro-Oeste: a Escola de Circo Laheto", de Maneco Maracá e Larissa de Paula, inicia-se com uma breve narrativa das origens do circo social no Centro-Oeste do Brasil, um movimento que teve início em meados de 1970 na cidade de São Felix do Araguaia (MT), passou por Belo Horizonte (MG) até chegar a Goiânia (GO) em 1994, onde se reestruturou através da criação do Grupo de Teatro Laheto, posteriormente renomeado como Circo Laheto. Os diversos projetos artísticos e 
socioeducativos desenvolvidos por essa escola seguem uma orientação metodológica libertadora, integrando arte circense à educação popular e ao trabalho coletivo e pautando-se na luta pelos direitos da criança e do adolescente.

O capítulo 10, "A arte como fomentadora do desenvolvimento humano: um estudo com adolescentes em Mogi-Mirim/SP”, de Maria Isabel Somme e Maria Rosa de Camargo, é a síntese de uma pesquisa realizada com a ONG Incentivo à Criança e ao Adolescente, um projeto social estabelecido na cidade de Mogi-Mirim (SP) que visa assistir jovens entre 13 e 17 anos através do ensino de atividades circenses. As autoras discutem o sentido da arte e das atividades criativas como espaços privilegiados de formação humana.

No capítulo 11, "Circo, desenvolvimento e educação infantill", Ademir de Marco apresenta, através de uma substancial revisão de literatura, aproximações possíveis e desejáveis entre os jogos circenses, mais especificamente o malabarismo, e o desenvolvimento integral da criança, um processo complexo que abarca aspectos psicológicos, neurológicos, motores, cognitivos, sociais e culturais.

O capítulo 12, "As relações humanas na pedagogia do circo social desenvolvidas pela Escola Pernambucana de Circo", de Maria de Fátima Pontes, é um relato sobre a Escola Pernambucana de Circo, fundada por Zezo Oliveira na cidade de Recife (PE) e concebida como um projeto de inclusão na perspectiva do circo social. A autora apresenta uma pequena síntese das estratégias pedagógicas desenvolvidas, ressaltando que a dimensão artística não é negligenciada, pois, além das aulas, existe uma agenda de espetáculos realizados pela Trupe Circus, um grupo de performance integrado por jovens de 16 a 29 anos formados pela Escola Pernambucana de Circo.

O último capítulo, "As atividades circenses na FEF-UNICAMP: a construção de uma nova área de estudos e pesquisa", de Marco Bortoleto, Rodrigo Duprat e Bruno Tucunduva, traz uma descrição dos experimentos circenses realizados na Faculdade de Educação Física da UNICAMP desde o início de 1990. Essas aventuras, de alguma forma, prepararam o terreno para a fundação do Circus, grupo de estudos fundado em 2006 e que se apresenta atualmente como um dos polos mais expressivos da pesquisa em artes circenses no Brasil, fomentando também o desenvolvimento de projetos artísticos e sociais em conjunto com grupos e instituições nacionais e internacionais de referência. Para os autores, uma das maiores conquistas do Circus se deu através da criação e da oferta, a partir de 2006, de uma disciplina eletiva sobre as atividades circenses vinculada à graduação em Educação Física, um espaço privilegiado de cultivo e disseminação dos saberes circenses.

Circo: horizontes educativos é o resultado de mais de dez anos de muito trabalho em prol da valorização das artes circenses na contemporaneidade, um processo pautado na necessidade de estabelecer parcerias legítimas entre artistas, educadores e pesquisadores de todo Brasil e exterior. O projeto da obra foi contemplado pelo Prêmio Carequinha de Estímulo ao Circo (modalidade pesquisa), promovido pela Fundação Nacional de Artes (MinC/FUNARTE).

A coletânea é ainda um convite para meditarmos sobre o lugar da arte, da tradição e da cultura na construção de um modo de vida mais praticável, mais criativo e que valorize aqueles despretensiosos afetos de alegria tão facilmente encontrados na fruição de um evento circense.

\section{Referências}

Bortoleto, M. A. C.; BARRAGÁn, T. O.; SIlVA, E. (Org.). Circo: horizontes educativos. Campinas, SP: Autores Associados, 2016. 257 p. 
Recebido em: 27/02/2018

Revisado em: 21/06/2018

Aprovado em: 25/07/2018

Endereço para correspondência:

joserafaelmadureira@gmail.com

José Rafael Madureira

Universidade Federal de Maceió

Av. Lourival Melo Mota, S/N

Tabuleiro do Martins

Maceió - AL

CEP 57072-900 